University of Nebraska - Lincoln

DigitalCommons@University of Nebraska - Lincoln

3-2009

\title{
Avoidance-Suppressing Effect of Antipsychotic Drugs Is Progressively Potentiated After Repeated Administration: An Interoceptive Drug State Mechanism
}

\author{
Alexa Lucille Mead \\ University of Nebraska-Lincoln \\ Ming Li \\ University of Nebraska-Lincoln, mli2@unl.edu
}

Follow this and additional works at: https://digitalcommons.unl.edu/psychfacpub

Part of the Psychiatry and Psychology Commons

Mead, Alexa Lucille and Li, Ming, "Avoidance-Suppressing Effect of Antipsychotic Drugs Is Progressively Potentiated After Repeated Administration: An Interoceptive Drug State Mechanism" (2009). Faculty Publications, Department of Psychology. 405.

https://digitalcommons.unl.edu/psychfacpub/405

This Article is brought to you for free and open access by the Psychology, Department of at DigitalCommons@University of Nebraska - Lincoln. It has been accepted for inclusion in Faculty Publications, Department of Psychology by an authorized administrator of DigitalCommons@University of Nebraska - Lincoln. 
Published in Journal of Psychopharmacology v. 23, no. 2 (March 2009; 9 p.). Copyright 2009, Sage. Used by permission.

\title{
Avoidance-Suppressing Effect of Antipsychotic Drugs Is Progressively Potentiated After Repeated Administration: An Interoceptive Drug State Mechanism
}

\author{
Alexa Lucille Mead, Department of Psychology, University of Nebraska-Lincoln, USA \\ Ming Li, Department of Psychology, University of Nebraska-Lincoln, USA (mli2@unl.edu)
}

Abstract

Antipsychotic drugs selectively suppress conditioned avoidance response. Using a two-way active avoidance response paradigm, we examined the role of druginduced interoceptive state in the mediation of avoidance-suppressive effect. In Experiment 1, we found that rats intermittently treated with olanzapine (OLZ) $(1.0$ $\mathrm{mg} / \mathrm{kg}$, s.c.) or haloperidol $(0.03 \mathrm{mg} / \mathrm{kg}$, s.c. $)$ on the $1 \mathrm{st}$ day of a 3-day cycle for seven cycles exhibited a progressive across-session decline in avoidance responding, despite the fact that they exhibited a comparable high level of avoidance responding on the 3rd day of each cycle during the drug-free retraining session. In Experiments 2 and 3, rats that were previously treated with OLZ (0.5-2.0 mg/ $/ \mathrm{kg}$, s.c.) or risperidone $(0.2-1.0 \mathrm{mg} / \mathrm{kg})$

\section{Introduction}

Rat conditioned avoidance response (CAR) model is an instrumental conditioning paradigm, in which rats are trained to make an active motor response to avoid footshock (Bolles, 1970). In a typical CAR experiment, a rat is placed in a two-compartment shuttle box and presented with a conditioned stimulus (CS, e.g., white noise), followed by an aversive unconditioned stimulus (US, e.g., footshock). After several CS-US pairings, the rat typically runs from one compartment to another during the CS (before the onset of the US), hence, avoiding the US.

The CAR model is a well-established preclinical test for antipsychotic activity with high predictive validity (Arnt, 1982; Natesan, et al., 2006; Wadenberg, et al., 2001). All currently used antipsychotic drugs at the clinical relevant doses, selectively suppress avoidance responding while leaving escape response intact. In contrast, anxi- during the acquisition phase of avoidance conditioning exhibited significantly fewer avoidance responses when they were retested 3 weeks later to the same drug in comparison to rats that were previously treated with nonantipsychotic drugs (chlordiazepoxide, $10 \mathrm{mg} / \mathrm{kg}$, citalopram $10 \mathrm{mg} / \mathrm{kg}$, or sterile water). Overall, these findings indicate a 'drug memory'-like mechanism that maintains the avoidance-suppressing effect of antipsychotics over time. This mechanism is likely driven by the interoceptive state caused by the antipsychotics, which may also be an important behavioral mechanism mediating the clinical effects of antipsychotic treatments.

Key words: conditioned avoidance response; drug memory; haloperidol; interoceptive drug state; olanzapine; rat; risperidone olytics and antidepressants do not have this selectivity. Thus, the antiavoidance effect is frequently used as a validated behavioral index of 'antipsychotic' property. Most work in preclinical psychopharmacology has used the rat CAR model as a simple screening tool to identify chemical compounds with potential antipsychotic activity, and the majority of the work relies on the acute treatment effect. Little attention, however, has been paid to understand the behavioral mechanisms underlying the antiavoidance effect of antipsychotics. We recently addressed this issue ( $\mathrm{Li}, 2007)$. We used a repeated drug treatment regimen to better mimic clinical treatment conditions and found that rats treated with haloperidol (HAL), risperidone (RIS), or olanzapine (OLZ) daily for 7 consecutive days showed a progressive across-session decline in avoidance responding. We also found that rats previously treated with HAL and retested under the same dose of HAL after their avoidances recovered to the pre- 
Mead \& Li in Journal of Psychopharmacology 23 (2009)

drug level, still showed fewer avoidances than when they were first tested. This finding indicates that HAL treatment may induce a 'memory-like' mechanism that allows the animal to 'remember' how to perform under the influence of drug in the avoidance responding situation. This 'memory-like' mechanism is likely driven by the interoceptive state caused by the antipsychotics (Overton, 1979; Schechter and Cook, 1975) and may play an important role in the maintenance of decreased avoidance responding across sessions.

The notion that the drug-induced interoceptive state(s) may be directly involved in the antipsychotic effects is relatively new, although preclinical studies such as those based on drug discrimination and state-dependent learning have long recognized the distinct drug states induced by typical and atypical antipsychotics (Goudie, et al., 1998; Overton, 1979; Porter, et al., 2005; Porter, et al., 2000). In this study, we report three experiments that further examined the role of the antipsychotic-induced interoceptive state in the antiavoidance (antipsychotic) effects of antipsychotic drugs. In Experiment 1, using a between-subjects design and an intermittent (on-off-on) drug treatment regimen, we tested the effects of repeated HAL $(0.03 \mathrm{mg} / \mathrm{kg}$, s.c.) and OLZ $(1.0 \mathrm{mg} / \mathrm{kg}$, s.c.) treatment (once every $72 \mathrm{~h}$ ) on avoidance responding over seven nonconsecutive test sessions. During the 'off' days, rats were retrained drug-free to maintain a high level of avoidance. We found the same progressively enhanced disruption on avoidance responding, as we observed in rats tested in the consecutive schedule, despite the fact that they all exhibited a high level of avoidance immediately prior to each drug session (e.g. during the drug-free retraining sessions). In the subsequent HAL tests, when all the rats were tested under HAL $(0.03 \mathrm{mg} / \mathrm{kg}$, s.c.), those that were previously treated with OLZ showed significantly lower avoidance responding than did those that had previously received the vehicle, even though both groups were exposed to HAL for the first time, suggesting that the antipsychotic drug state induced by OLZ may have some similarities to that induced by HAL. In Experiments 2 and 3, we examined this mechanism by giving naive rats various doses of OLZ (Experiment 2) or RIS (Experiment 3) during the acquisition phase of avoidance conditioning, retrained them drug-free for a period of 3 weeks, and then tested their avoidance responding under OLZ (1.0 mg/kg, s.c.) or RIS (0.33 mg/ $\mathrm{kg}$, s.c.). We reasoned that if the antipsychotic-induced interoceptive drug state is one of the mechanisms that maintain the antiavoidance effect of antipsychotics over time, we should still be able to observe that rats previously treated with OLZ or RIS during the acquisition phase (before the acquisition of avoidance behavior) would still show a stronger response to OLZ or RIS respectively after they had acquired high avoidance response. Results were consistent with our prediction.

\section{Materials and methods}

Animals

Male Sprague-Dawley rats (226-250 g upon arrival, Charles River, Portage, MI) were housed two per cage, in $48.3 \times 26.7 \times 20.3 \mathrm{~cm}$ transparent polycarbonate cages lined with aspen shavings. The colony temperature was maintained at $21 \pm 1^{\circ} \mathrm{C}$ with a relative humidity of $55 \%$ $60 \%$, with water and food available ad libitum. All behavioral tests were conducted during the light phase of a 12 h light-dark cycle (with light on between 6:00 a.m. and 6:00 p.m.). Rats were allowed at least 1 week of habituation to the animal facility before being used in experiments. All protocols were approved by the University of Nebraska-Lincoln Animal Care and Use Committee.

\section{Drugs}

The injection solutions of HAL (5 mg/mL, Sabex Inc, Quebec, Canada) and chlordiazepoxide (CDP, SigmaAldrich, St. Louis, MO) were obtained by mixing drugs with sterile water. OLZ (Toronto Research Chemicals Inc, Ontario, Canada) and RIS (a gift from the NIMH drug supply program) were dissolved in $1 \%-1.5 \%$ glacial acetic acid in sterile water. Citalopram (CIT, Toronto Research Chemicals Inc., Ontario, Canada) was dissolved in $0.9 \%$ physiological saline. HAL, OLZ, RIS, and CIT were administered subcutaneously (s.c.) $1 \mathrm{~h}$ before avoidance training or testing, whereas CDP was injected $0.5 \mathrm{~h}$ before avoidance training ( $\mathrm{Li}$, et al., 2007).

\section{Apparatus}

Six identical two-way shuttle boxes custom designed and manufactured by Med Associates (St. Albans, VT) were used. Each box was housed in a ventilated, soundinsulated isolation cubicle $(96.52 \mathrm{~cm} \mathrm{~W} \times 35.56 \mathrm{~cm} \mathrm{D} \times$ $55.88-63.5 \mathrm{~cm} \mathrm{H})$. Each box was $64 \mathrm{~cm}$ long, $30 \mathrm{~cm}$ high (from grid floor), and $24 \mathrm{~cm}$ wide and was divided into two equal-sized compartments by a partition with an arch style doorway $(15 \mathrm{~cm}$ high $\times 9 \mathrm{~cm}$ wide at base). A barrier ( $4 \mathrm{~cm}$ high) was placed between the two compartments, so the rats had to jump from one compartment to the other. The grid floor consisted of 40 stainless-steel rods with a diameter of $0.48 \mathrm{~cm}$, spaced $1.6 \mathrm{~cm}$ apart center to center, through which a scrambled footshock (US, $0.8 \mathrm{~mA}$, maximum duration: $5 \mathrm{~s}$ ) was delivered by a constant current shock generator (Model ENV410B) and scrambler (Model ENV-412). Illumination was provided by two houselights mounted at the top of each compartment. The CS was a $76 \mathrm{~dB}$ white noise produced by a speaker (ENV 224 AMX) mounted on the ceiling of the cubicle, centered above the shuttle box. Background noise (approximately $74 \mathrm{~dB}$ ) was provided by a ventilation fan affixed at the top corner of each isolation cubicle. All training and testing procedures were controlled by Med Associates programs running on a computer. 


\section{Avoidance conditioning and testing procedure}

A regular training/testing session consisted of either 20 or 30 trials (see below for details). Each trial started with the presentation of white noise (CS) for $10 \mathrm{~s}$, followed by a continuous scrambled footshock (maximum duration $=5 \mathrm{~s}, 0.8 \mathrm{~mA}$, US) on the grid floor. If a subject moved from one compartment to the other within the $10 \mathrm{~s}$ of CS presentation, it avoided the shock, and this shuttling response was recorded as avoidance.If the rat remained in the same compartment for more than $10 \mathrm{~s}$ and made a crossing upon receiving the footshock, this response was recorded as escape. If the rat did not respond during the entire presentation of the shock, the trial was terminated and escape failure was recorded.

\section{Statistical analysis}

The number of avoidance responses was used as the main dependent variable. Avoidance data from the repeated drug test sessions were expressed as mean values \pm SEM and were analyzed using a factorial repeated measures analysis of variance (ANOVA) with the between-subjects factor being treatment groups (e.g. HAL, OLZ, RIS etc.), and the within-subjects factor being the drug test sessions. To identify the group difference on specific test sessions, one-way ANOVAs followed by post-hoc Tukey (HSD) tests (for more than three groups) or independent-samples T-tests (for two-group comparisons) were used. A conventional two-tailed level of significance at the $5 \%$ level was required.

Experiment 1: Effects of repeated intermittent HAL $(0.03 \mathrm{mg} / \mathrm{kg})$ or OLZ $(1.0 \mathrm{mg} / \mathrm{kg})$ treatment on avoidance responding This experiment was designed to examine the role of antipsychotic-induced interoceptive state in the potentiation of the antiavoidance effect of repeated antipsychotic treatment, using an intermittent 'on-offon' 3-day treatment/test schedule. This schedule consisted of seven 3-day treatment/test cycles. The first day was a drug treatment and CAR test session. Well-trained rats ( $>70 \%$ avoidance in the last two training sessions) were injected with HAL ( $0.03 \mathrm{mg} / \mathrm{kg}$, s.c.), OLZ $(1.0 \mathrm{mg} /$ $\mathrm{kg}$, s.c.), or vehicle (sterile water) and tested in a 30-trial CAR session. The second day was a drug-free resting day, and the third day was a drug-free CAR retraining day when all rats were retrained in the 30-trial CAR session. This cycle repeated for seven times. This schedule ensured that immediately before each cycle of drug test, the rats' avoidance responding was recovered back to the predrug level. If the drug-induced interoceptive state is one of the important behavioral mechanisms underlying the potentiated antiavoidance effect associated with repeated drug treatment, we would expect to see lower avoidance only during the drug test sessions, and a progressive decline in avoidance responding across the drug sessions. Another advantage of this schedule was that it minimizes the possibility of drug accumulation, so the observed potentiated effect could only be attributed to the drug cue. At the end of this intermittent schedule, all rats were tested under HAL $(0.03 \mathrm{mg} / \mathrm{kg}$, s.c. $)$ for three consecutive sessions to examine whether previous OLZ experience potentiated later response to HAL as a way of assessing the similarity between the HAL-induced and OLZ-induced interoceptive states.

\section{Experimental procedure}

A total of 30 rats were first habituated to the avoidance boxes for 2 days. On each day, rats were placed in the box and allowed to explore the entire box for $20 \mathrm{~min}$. Rats were then trained for a total of eleven sessions (30 trials/session) over a 17-day period. At the end of the training session, 23 rats had reached training criterion (at or above $70 \%$ avoidance, or 21 trials, by the last 2 training days), and they were randomly assigned to three groups ( $n=7$ vehicle, $n=8 \mathrm{HAL}, n=8 \mathrm{OLZ}$ ) and started the intermittent 'on-off-on' 3-day treatment/test schedule. On Day 1 , rats were injected with HAL $(0.03 \mathrm{mg} / \mathrm{kg})$, OLZ $(1.0 \mathrm{mg} / \mathrm{kg})$, or vehicle (sterile water) subcutaneously 1 $\mathrm{h}$ before being placed in the apparatus and tested. The same procedure as used during the training was used for the drug testing. On Day 2, rats were left alone in their home cages. On Day 3, rats were retrained. This cycle repeated for seven times over a period of 21 days. One day after the end of the seventh cycle, all three groups were injected with HAL $(0.03 \mathrm{mg} / \mathrm{kg}$, s.c. $)$ and tested for three additional sessions.

Experiment 2: Effects of OLZ treatment (0.5, 1.0 and 2.0 $\mathrm{mg} / \mathrm{kg}$ ) during the avoidance training on later avoidance responding to OLZ $(1.0 \mathrm{mg} / \mathrm{kg})$ This experiment examined whether previous drug experience during the acquisition phase of CAR might persist and cause a potentiated OLZ response later. Forty-five rats were randomly assigned to five groups ( $n=9 /$ group): vehicle (sterile water), OLZ 0.5, 1.0, $2.0 \mathrm{mg} / \mathrm{kg}$, and CDP 10.0 $\mathrm{mg} / \mathrm{kg}$. After 2 days of habituation to the CAR boxes, all rats were trained in a 20-trial CAR session for 7 consecutive days. Each daily training session started $1 \mathrm{~h}$ after the OLZ or vehicle injection, or $30 \mathrm{~min}$ after CDP injections. One day later, the learning effect was assessed in three drug-free avoidance testing sessions in which only the CS was presented for 20 trials (no shock US). During these 10 days of the training/testing period, the rat's body temperature was also measured, using a probe (lubricated with mineral oil) inserted in the rectum (Thermalert TH-5, Physitemp, Clifton, NJ, USA) before and after each session. Because these data were not relevant to the question addressed here, they were not reported here but were reported in a separate paper (Mead, et al., 2008). After 3 days of resting, all rats were retrained (drugfree) to reacquire avoidance responding in 10 sessions (30 trials/ session) over 15 days. At the end of the training session, 35 rats had reached the training criteria (at or above $70 \%$ avoidance on the last 2 training days). These rats were classified into two groups: one group consisting of rats that were previously treated with OLZ $(n=11$ of 
27 rats, OLZ 0.5, 1.0, $2.0 \mathrm{mg} / \mathrm{kg}$, s.c., collectively termed the 'Olanzapine Experience' group), and one group consisting of rats that were previously treated with either vehicle orCDP $(n=13$ of 18 , termed the 'No Olanzapine Experience' group). They were then treated with $1.0 \mathrm{mg} /$ $\mathrm{kg}$ of OLZ and tested for 3 consecutive days.

Experiment 3: Effects of RIS treatment (0.2, 0.33, and 1.0 $\mathrm{mg} / \mathrm{kg}$ ) during the avoidance training on later avoidance responding to RIS $(0.33 \mathrm{mg} / \mathrm{kg})$ This experiment was identical to Experiment 2 with the following exceptions. First, 48 rats were used and randomly assigned to six groups ( $n=8 /$ group): vehicle (sterile water), RIS 0.2 , $0.33,1.0 \mathrm{mg} / \mathrm{kg}$, CDP $10.0 \mathrm{mg} / \mathrm{kg}$ and CIT $10.0 \mathrm{mg} / \mathrm{kg}$. Second, during the seven daily CAR test sessions under drug and three daily CAR drug-free test sessions, all rats were also tested for the startle reflex immediately after being removed from the CAR boxes (these data were not relevant to this study and are not reported here). All rats were then retrained (drug-free) to reacquire avoidance responding in ten sessions ( 30 trials/session) over 18 days. After retraining, 45 rats had reached training criteria (at or above $70 \%$ avoidance on the last two training days). These rats were classified into two groups: one group consisting of rats that were previously treated with RIS ( $n=22$, termed the 'Risperidone Experience' group), and one group consisting of rats that were previously treated with either vehicle, CDP or CIT ( $n=23$, termed the 'No Risperidone Experience' group). They were then treated with $0.33 \mathrm{mg} / \mathrm{kg}$ of RIS and tested for 3 consecutive days.

\section{Results}

Experiment 1: Effects of intermittent HAL $(0.03 \mathrm{mg} / \mathrm{kg})$ or OLZ $(1.0 \mathrm{mg} / \mathrm{kg})$ treatment on avoidance responding

Figure 1A shows the effects of intermittent HAL and OLZ treatment on avoidance responding across the seven test cycles. Both HAL and OLZ suppressed avoidance responding on the first drug day, and this effect was potentiated with each subsequent drug test (a progressive across-session decline). Interestingly, on all drug-free retraining days, avoidance responding in both groups fully recovered back to the predrug levels. On the contrary, rats treated with vehicle maintained a high level of avoidance responding throughout the entire testing period. This observation was confirmed by statistical analysis. A repeated measures ANOVA using 'Drug Session' as a within-subject factor and 'Treatment Group' as a between-subjects factor showed a significant main effect of 'Treatment Group' $\left(F_{(2,20)}=20.724, P<0.001\right)$, 'Drug Session' $\left(F_{(6,120)}=14.017, \stackrel{P}{2}<0.001\right)$, and a 'Treatment Group' × 'Drug Session' interaction $\left(F_{(2,20)}=13.987\right.$, $P<0.001)$. Individual one-way ANOVAs and post hoc Tukey tests on each drug-testing day showed that the OLZ group differed significantly from the vehicle group on each day (Figure 1A, all Ps < 0.003), and HAL differed significantly from the vehicle group on days 4 through 7 (all $\left.P_{\mathrm{s}}<0.05\right)$.
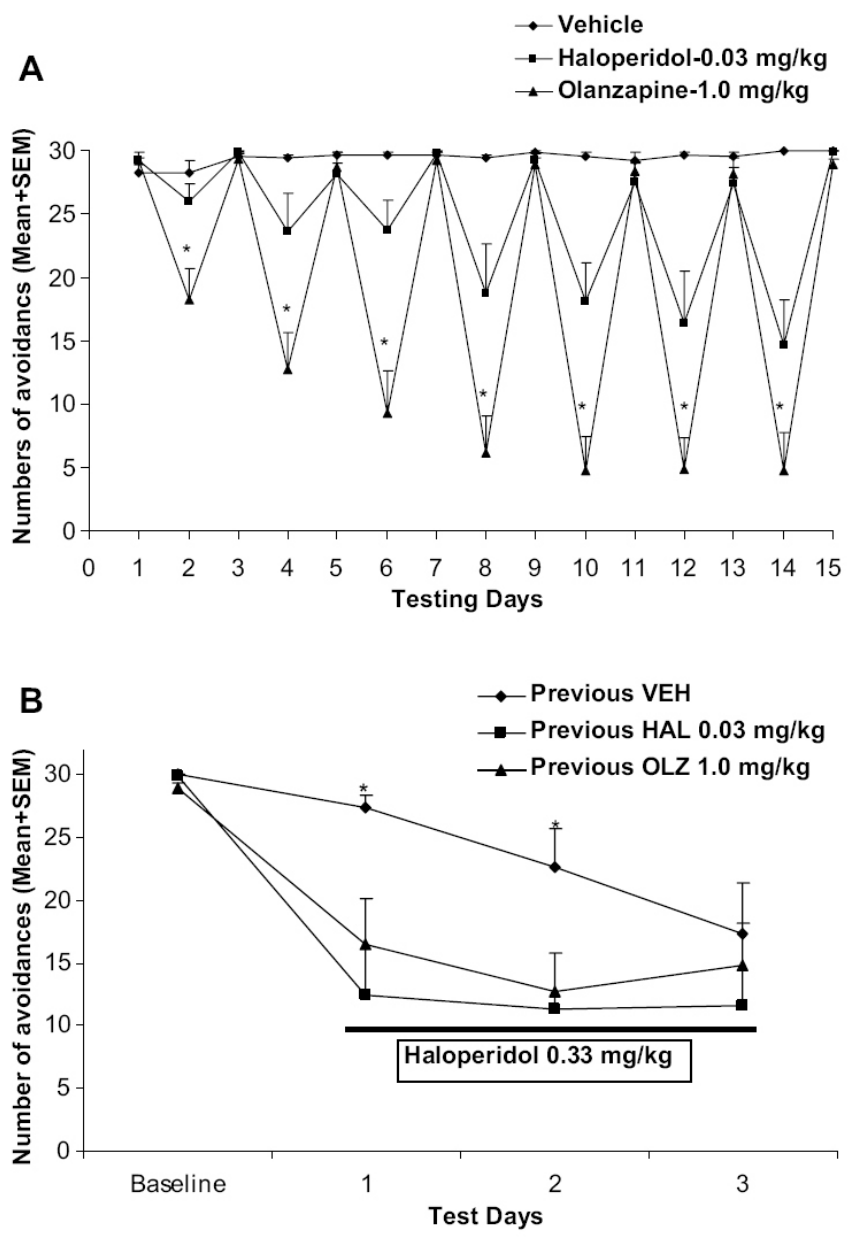

Figure 1 Effects of intermittent antipsychotic treatments on conditioned avoidance responding. Each point represents mean avoidance levels + SEM. Intermittent $0 \mathrm{LZ}(1.0 \mathrm{mg} / \mathrm{kg}$, s.c., $-60 \mathrm{~min})$ or $\mathrm{HAL}(0.03 \mathrm{mg} / \mathrm{kg}$, s.c., $-60 \mathrm{~min}$ ) treatment significantly disrupted avoidance responding across the seven test sessions. Throughout the test sessions, the disruptive effect was progressively enhanced. Figure $1 \mathrm{~A}$ : Repeated intermittent HAL and $0 \mathrm{LZ}$ treatment causes an across-session decline across seven drug sessions. ' * ' indicates a significant difference between the OLZ group and the vehicle group. Figure 1B: Three HAL treatment days following the 7 previous drug treatment days. "*' indicates a significant difference between the vehicle group and both the OLZ and HAL group.

To examine the similarity between the HAL and OLZinduced drug state mediating avoidance, and whether previous antipsychotic treatment potentiated later response to HAL, all rats were treated with HAL $(0.05$ $\mathrm{mg} / \mathrm{kg}$, s.c.) for three consecutive days 3 days after the last retraining test (see Figure 1B). An independent-samples $T$-test revealed the previously HAL-treated group showed significantly lower avoidance responses than the previously vehicle-treated group on days 1 and 2 (Day 1 : $t(13)=3.443, P=0.004$, Day 2: $t(13)=2.412, P=0.031)$, indicating a potentiated effect of previous HAL treatment. The previously OLZ-treated group also differed significantly from the vehicle group on days 1 and 2 (Day 1: $t(13)=2.879, P=0.021$, Day 2: $t(13)=2.218, P=0.045)$, suggesting that previous OLZ treatment also potentiated the HAL effect, and there was a similarity between the 
HAL and OLZ-induced interoceptive states. The previously OLZ-and HAL-treated groups did not differ from each other on any day (all Ps $>0.05$ ).

Experiment 2: Effects of OLZ treatment $(0.5,1.0$ and $2.0 \mathrm{mg} /$ $\mathrm{kg}$ ) during the avoidance training on later avoidance responding to OLZ $(1.0 \mathrm{mg} / \mathrm{kg})$

OLZ treatment severely impaired the acquisition of avoidance responding. Rats repeatedly treated with three different doses of OLZ $(0.5,1.0,2.0 \mathrm{mg} / \mathrm{kg})$ during the acquisition phase of the CAR paradigm did not show any improvement in avoidance responding (Figure 2A). In contrast, rats treated with CDP, $10 \mathrm{mg} / \mathrm{kg}$ or vehicle

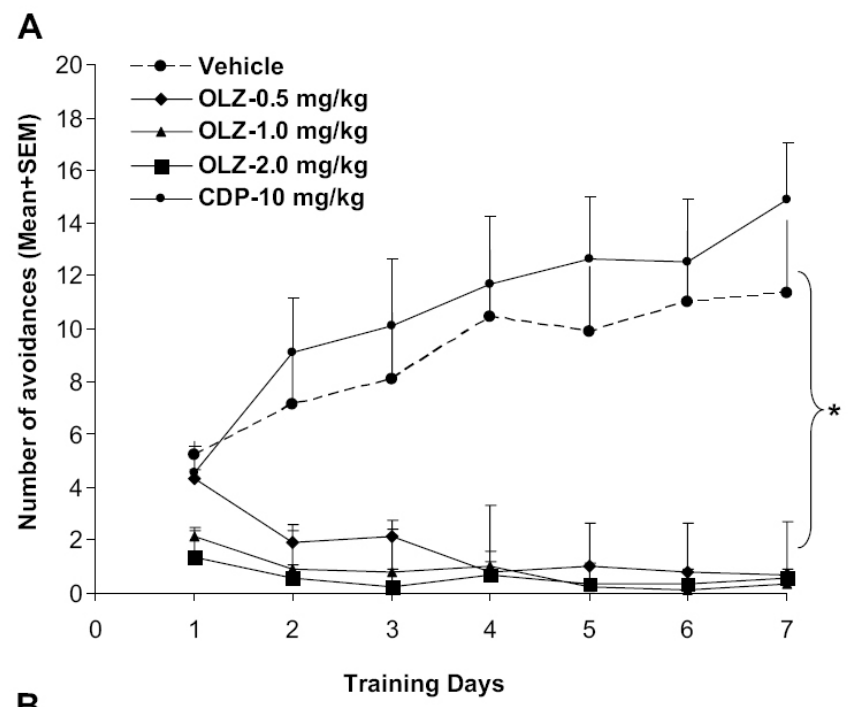

B

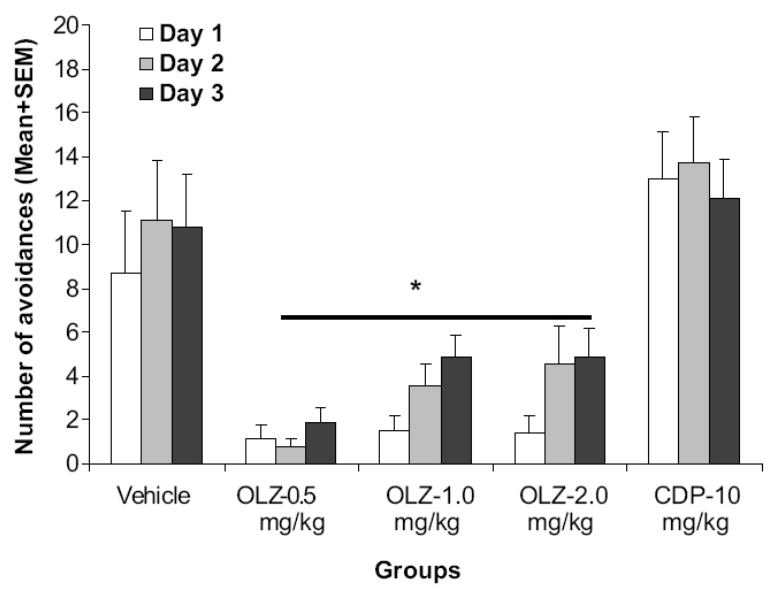

Figure 2 Mean (+SEM) numbers of avoidance responses of the five groups of rats that were trained under $0 \mathrm{LZ} 0.5,1.0$ and $2.0 \mathrm{mg} / \mathrm{kg}$, CDP $10.0 \mathrm{mg} / \mathrm{kg}$ or vehicle treatment over the 7 avoidance conditioning days (A) and on the three drug-free testing days following 7 days of drugtesting (B). ${ }^{*} P<0.05$ significantly different from the vehicle group. Please note that this figure was first reported in Mead, et al. (2008) as Figure 7. (distilled water) showed a steady improvement throughout the training phase (repeated measures ANOVAs: a significant main effect of 'Treatment': $F_{(4,40)}=15.489, P$ $<0.001$; 'Sessions': $F_{(6,240)}=3.506, P=0.002$; and 'Treatment' $\times$ 'Sessions' interaction, $\left.F_{(24,240)}=5.745, P<0.001\right)$. In the three subsequent drug-free CS-only test days, as shown in Figure 2B, the OLZ rats still showed significantly lower avoidance responses than the other groups (all $P_{\mathrm{s}}<0.05$ ). Detailed analysis of avoidance response data was reported in Mead, et al. (2008).

After the 10 sessions of drug-free retraining, only those rats that exhibited more than $70 \%$ avoidances in the last two retraining sessions were used in the OLZ retests. As can be seen in Figure 3, before the OLZ treatment, both the OLZ experienced group and the nonexperienced group had almost identical mean avoidance responses. However, upon retesting, the rats with previous OLZ experience showed a much lower level of avoidance responding than those with no previous OLZ experience over the three test sessions. Independent-samples T-tests showed that there were significant differences on Day 1 $(t(33)=-5.536, P<0.001)$, Day $2(t(33)=-3.133, P=0.006)$ and Day $3(t(33)=-3.344, P=0.004)$.

Experiment 3: Effects of RIS treatment (0.2, 0.33, and $1.0 \mathrm{mg} /$ $\mathrm{kg}$ ) during the avoidance training on later avoidance responding to RIS $(0.33 \mathrm{mg} / \mathrm{kg})$

Rats treated with $10 \mathrm{mg} / \mathrm{kg}$ of CDP), $10 \mathrm{mg} / \mathrm{kg}$ of CIT, or vehicle (distilled water) showed a steady improvement throughout the training phase. RIS treatment dose dependently impaired the acquisition of avoidance responding as the RIS 1.0 group-but not RIS 0.2 and RIS 0.33 groups-showed fewer avoidances than the vehicle group (Tukey HSD test, $P<0.001$ ). In the three subsequent drug-free CS-only test days, as shown in Figure 4B,

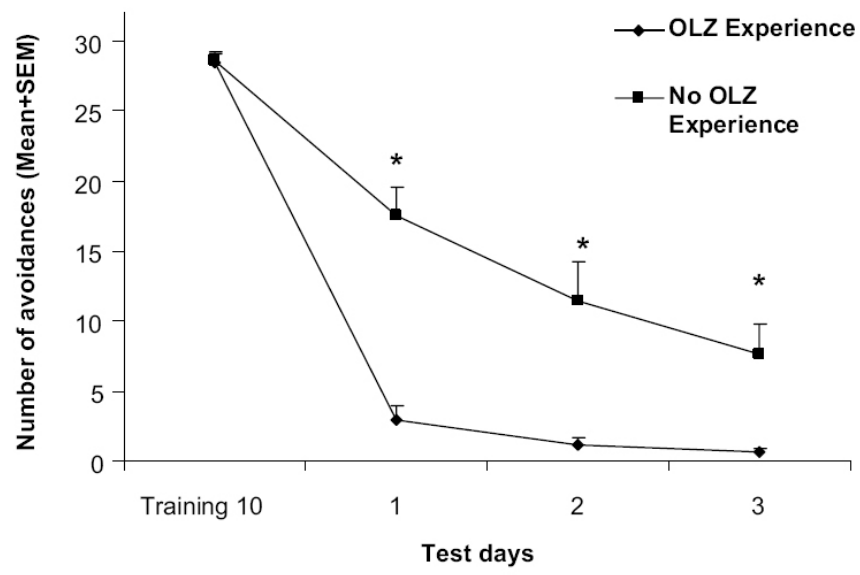

Figure 3 Effects of OLZ retreatment $(1.0 \mathrm{mg} / \mathrm{kg}$, s.c., $-60 \mathrm{~min})$ on the rats that were previously treated with $0 \mathrm{LZ}(0.5,1.0$ or $2.0 \mathrm{mg} / \mathrm{kg}$, termed 'OLZ experienced') or other drugs (CDP $10 \mathrm{mg} / \mathrm{kg}$ or sterile water, termed 'No $0 \mathrm{LZ}$ experienced') during the acquisition phase. 

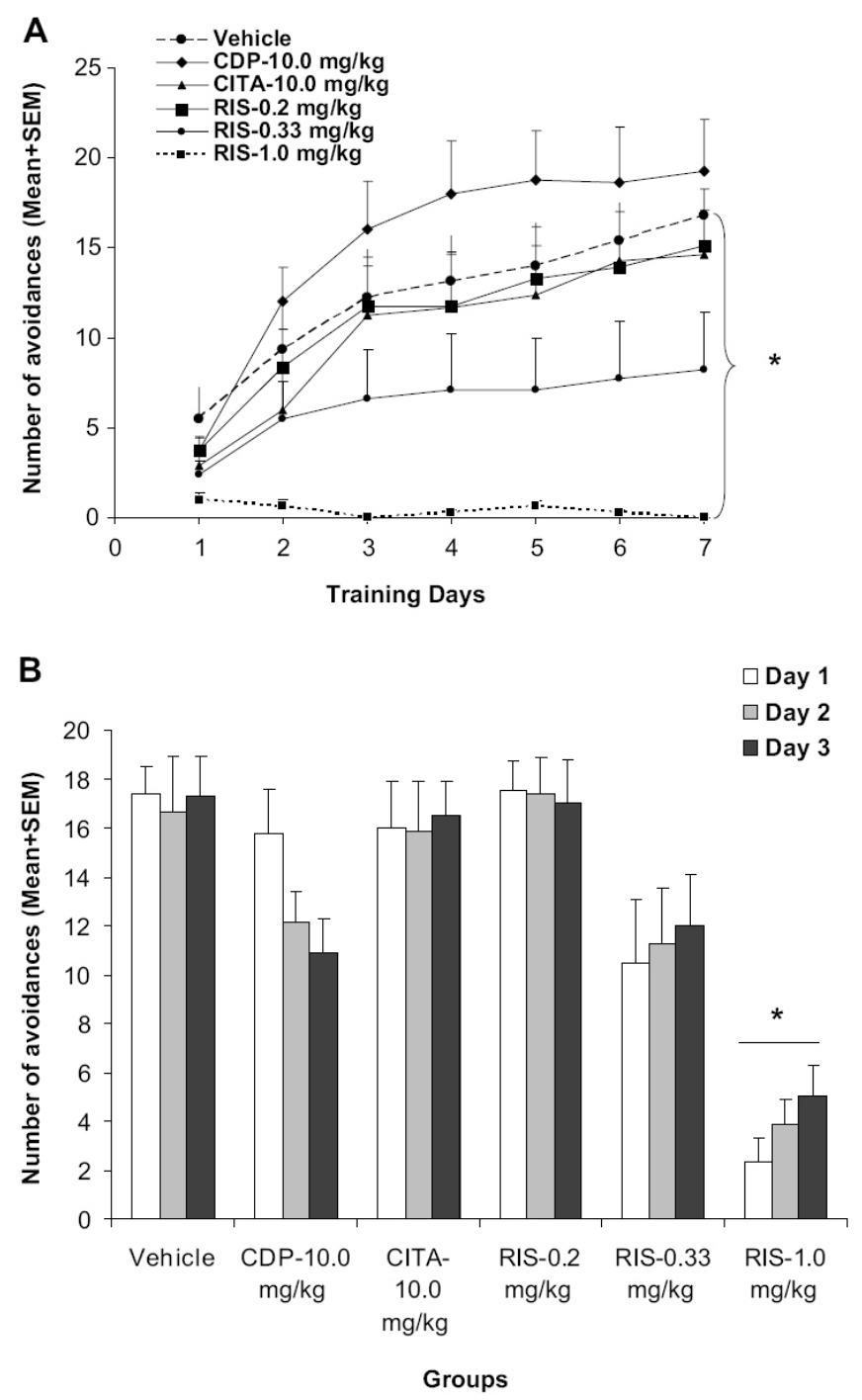

Figure 4 Mean (+SEM) numbers of avoidance responses of the six groups of rats that were trained under risperidone (RIS $0.2,0.33$ and $1.0 \mathrm{mg} / \mathrm{kg}$ ), chlordiazepoxide (CDP $10.0 \mathrm{mg} / \mathrm{kg}$ ), citalopram (CIT $10 \mathrm{mg} / \mathrm{kg}$ ) or vehicle treatment over the 7 avoidance conditioning days $(A)$ and on the three drug-free testing days following 7 days of drug-testing (B). ${ }^{*} P<0.05$ significantly different from the vehicle group.

only the RIS 1.0 group showed significantly fewer avoidance responses than the other drug groups $(P<0.001)$.

After the 10 sessions of drug-free retraining, only those rats that exhibited more than $70 \%$ avoidances in the last two retraining sessions were used in the RIS retests. As can be seen in Figure 5, before the RIS treatment, both the RIS experienced group and the nonexperienced group had almost identical mean avoidance responses. However, upon retesting, the rats with previous RIS experience showed a much lower level of avoidance responding than those with no previous RIS experience. Independent-samples $T$-tests showed that there was a significant

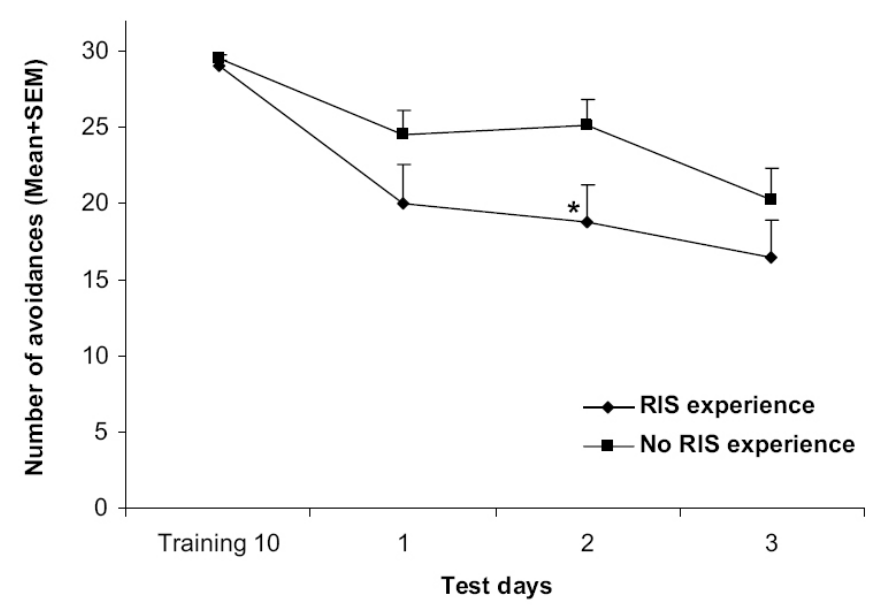

Figure 5 Effects of RIS retreatment $(0.33 \mathrm{mg} / \mathrm{kg}$, s.c., $-60 \mathrm{~min})$ on the rats that were previously treated with RIS $(0.2,0.33$ and $1.0 \mathrm{mg} / \mathrm{kg}$, termed 'RIS experienced') or other drugs (CDP $10 \mathrm{mg} / \mathrm{kg}$, CIT $10 \mathrm{mg} / \mathrm{kg}$ or sterile water, termed 'No RIS experienced') during the acquisition phase.

difference on Day $2(t(43)=-2.089, P<0.043)$, but not on Day $1(t(43)=-1.528, P=0.135)$ nor Day $3(t(43)=-1.157$, $P=0.254)$.

\section{Discussion}

Results from the three experiments provide additional support to the idea that antipsychotic-induced interoceptive state may be one of the important behavioral mechanisms underlying the potentiated antiavoidance effect of repeated antipsychotic treatments. In Experiment 1, we found that repeated intermittent antipsychotic treatment could reliably produce an across-session decline in avoidance responding. Rats repeatedly treated with HAL and OLZ every 3rd day, still exhibit an across-session decline despite the ability to return to high avoidance levels in between drug treatments. In addition, we found that when rats were tested under HAL $(0.03 \mathrm{mg} /$ $\mathrm{kg}$ ), those previously treated with OLZ showed significantly lower levels of avoidance responding than vehicle rats, even though both groups were treated with HAL for the first time. In Experiments 2 and 3, rats previously treated with OLZ or RIS during the acquisition phase showed significantly fewer avoidance responses than those without such a drug experience during the retests 3 weeks later, suggesting that rats that have experienced an antipsychotic may 'remember' that drug state and respond accordingly. This increase of anti-avoidance effect across multiple drug test sessions does not seem to reflect simple drug accumulation effect, as the half-lives of antipsychotics in the rat brain is $1.5 \mathrm{~h}$ for HAL (Cheng and Paalzow, 1992), $2.5 \mathrm{~h}$ for OLZ (Aravagiri, et al., 1999), and less than $4 \mathrm{~h}$ for RIS (van Beijsterveldt, et al., 1994), and we observed that the progressively potentiated anti- 
avoidance effect persisted for at least 3 days (Experiment 1) and over a 3-week period (Experiments 2 and 3).

In Experiment 1, we found that repeated intermittent HAL and OLZ treatment can reliably produce an acrosssession decline in avoidance responding. This finding is consistent with one of the experiments reported in $\mathrm{Li}$, et al. (2007). In that experiment, one group of well-trained rats (a within-subject design) received three doses of HAL from $0.03,0.05$, to $0.07 \mathrm{mg} / \mathrm{kg}$ (in this order) on an intermittent schedule, with drug-free retraining sessions inserted between two drug sessions. The rats were then tested a second time under the same drug schedule. The avoidance-disruptive effect of HAL at the same doses was much stronger in the 2 nd round than in the 1 st round. However, several limitations from that experiment prevent us from drawing a firm conclusion regarding the role of the interoceptive drug state in the antiavoidance potentiation. First, the exact source of the potentiated antiavoidance response seen in the 2nd round is not clear. This is because a higher dose of HAL (e.g. $0.07 \mathrm{mg} / \mathrm{kg}$ ) in the 1st round was always tested prior to a lower dose of HAL in the second round (e.g. $0.03 \mathrm{mg} / \mathrm{kg}$ ); thus, it is possible that the potentiated antiavoidance effect could be due to the repeated drug experience or due to the influence from the higher doses. Second, only HAL (a typical antipsychotic drug) was examined for the behavioral mechanism of antipsychotic action. Other anti-psychotics, such as atypicals like OLZ and RIS, were not examined. This study addressed these limitations, and the results suggest that even atypical drugs, such as OLZ and RIS, may work through a similar behavioral mechanism, e.g. by producing an antipsychotic-like interoceptive drug state that allows the animals to respond according to the drug state. Our results are also consistent with recent reports by Samaha, et al. $(2007,2008)$ who found that repeated intermittent HAL treatment (e.g. daily injection) gained efficacy in disrupting avoidance responding across multiple sessions. What is even more remarkable with our findings is the fact that this potentiated efficacy persists even after rats were off drug for weeks and being retrained, so that their avoidances were back at the pre-drug levels (see Figures 1A, 3, and 5). It appears that once a rat is exposed to an antipsychotic drug, this drug experience stays with it for a long period of time, and this memory-like drug effect is possibly mediated by the drug-induced interoceptive state. Behaviorally, an antipsychotic drug may act as an occasion setter (Maes and Vossen, 1997), which sets the condition in which rats behave on the basis of their previous drug experience in the avoidance testing context, or it may directly imprint the brain to create a drug 'memory trace' about avoidance responding under drug. This proposition may explain why continuous HAL treatment through osmotic minipumps lost efficacy in disrupting avoidance responding (Samaha, et al., 2008; Samaha, et al., 2007), as continuous drug treatment could not create a discrete drug state that is time-locked with the avoidance testing context. Thus, it may lose its occasion-setting property and not be able to direct animals' behavior in the avoidance testing situation. Using dopamine $\mathrm{D}_{2}$ receptor occupancy as a guide, Kapur, et al. (2003) suggests that antipsychotic administration through minipumps provides a better model of antipsychotic treatment in the clinic, as only this mode of drug administration produces clinical-relevant $\mathrm{D}_{2}$ occupancies $(60-80 \%)$, a condition found in patients with schizophrenia maintained on medications (Kapur, et al., 2003). On the basis of the current findings and that of Samaha, et al. (2007, 2008), it seems that although continuous drug administration provides a better model of pharmacodynamic and pharmacokinetic actions (e.g. $\mathrm{D}_{2}$ occupancy) of antipsychotics than intermittent treatment, it may not provide a better model of behavioral effects of antipsychotics, which show a progressive enhancement over time (Agid, et al., 2003; Kapur, et al., 2005), and only intermittent drug treatment in rats produces such a pattern of effects ( $\mathrm{Li}$, et al., 2007; Sun, et al., 2009).

So what are the possible neural bases of the drug statebased potentiated antipsychotic effect? We speculate that it may have something to do with the drug-induced brain changes, (e.g. neuroplasticity) because of its memorylike characteristics (Konradi and Heckers, 2001). These changes thus, might include elevations in the number and sensitivity of neuroreceptors (e.g. $\mathrm{D}_{2}$, receptors) (Samaha, et al., 2008; Samaha, et al., 2007), changes in the immediate early gene expressions (e.g. c-fos, zif268, $(\Delta \mathrm{FosB})$ (Grande, et al., 2004; Nguyen, et al., 1992; Robertson and Fibiger, 1992; Robertson, et al., 1994) and associated intracellular signaling pathways (e.g. DARPP-32, cAMP and PKA phosphorylation in the striatopallidal neurons) (Bateup, et al., 2008), or even adult neurogenesis (Kippin, et al., 2005). This issue needs further investigation.

The idea that antipsychotic-induced interoceptive state may be an important mechanism underlying the potentiated anti-avoidance effect with repeated treatment is also supported by the finding that rats that were previously treated with OLZ showed significantly lower levels of avoidance responding when tested under HAL than the rats previously treated with vehicle, although both groups were exposed to HAL for the first time. This finding suggests that the antipsychotic-induced interoceptive state is transferable between drugs that create a similar state (i.e. other antipsychotics with a different structure and receptor profile). This finding is complimentary to one of the findings from Li, et al. (2007). In that report, they found that rats previously treated with HAL continued to show the suppressed avoidance responding when switched to OLZ. Collectively, both findings suggest that there is a similarity between HAL and OLZ-induced antipsychotic-specific interoceptive state, as they can substitute for each other.

One prediction based on this drug (interoceptive state)- 
dependent memory mechanism is that even if the drug has been stopped and the avoidance responding has fully recovered back to the predrug level, during the next exposure to antipsychotic treatment, the animals with a previous drug experience should show a greater response - a prediction that was confirmed for both OLZ (Experiment 2 ) and RIS (Experiment 3). There is an interesting differential effect between the two widely prescribed drugs.

During the avoidance training phase, OLZ impaired the acquisition of avoidance response at all three dosage levels, whereas RIS suppressed the avoidance acquisition only at the highest dosage level. During the drug retests, OLZ showed a stronger reexposure effect, as it caused a significant group difference on each of the three test sessions, whereas RIS showed a weaker effect as it only caused a significant group difference on the second session. One possible explanation lies in the differences in the receptor binding profiles. OLZ has high affinity to dopamine $\mathrm{D}_{1}, \mathrm{D}_{2}, \mathrm{D}_{3}, \mathrm{D}_{4}$, serotonin 5- $\mathrm{HT}_{2}$, histaminic $\mathrm{H}_{1}$, $\mathrm{a}-1$ adrenergic and muscarinic $\mathrm{M}_{1}-\mathrm{M}_{5}$ receptors. RIS shows high affinity for $\mathrm{D}_{2}$ and $5-\mathrm{HT}_{2 \mathrm{~A}^{\prime}}$ as well as affinity for $\mathrm{D}_{1}, \mathrm{D}_{4}, \mathrm{a}-1$ adrenergic, and $\mathrm{a}-2$ adrenergic and histamine $\mathrm{H}_{1}$ receptors (Miyamoto, et al., 2005). The exact binding differences accounting for their differential potentiated effect in avoidance model are not clear and need future investigation. Another more likely explanation is the difference in the efficacy of OLZ and RIS doses used in the retests. OLZ at $1.0 \mathrm{mg} / \mathrm{kg}$ may be more efficacious than RIS at $0.33 \mathrm{mg} / \mathrm{kg}$, thus, producing a stronger potentiated effect. This point is also supported by the finding that OLZ $1.0 \mathrm{mg} / \mathrm{kg}$ impaired the acquisition of avoidance response, whereas RIS $0.33 \mathrm{mg} / \mathrm{kg}$ did not. It is thus possible that, had we used a higher dose of RIS (e.g. $1.0 \mathrm{mg} /$ $\mathrm{kg}$ ), we could have seen the same level of potentiation.

Clinical observations indicate that antipsychotic action starts early and increases in magnitude with repeated treatment (Agid, et al., 2003; Agid, et al., 2006; Emsley, et al., 2006; Glick, et al., 2006; Kapur, et al., 2005; Leucht, et al., 2005; Raedler, et al., 2007). However, animal models that faithfully capture this time course of action are few. This study represents an advance of our previous work (Li, et al., 2007) and further supports the idea that rat avoidance responding model based on the repeated drug treatment regimen is capable of mimicking several important features of clinical effects of antipsychotic treatment. It also provides a clue on the behavioral mechanism of antipsychotic action in the treatment of schizophrenia. Our previous work (Li, et al., 2007) and a recent one ( $\mathrm{Li}$, et al., accepted) suggest that antipsychotic drugs suppress avoidance responding by weakening the motivational salience of the CS. This observation, together with the current findings, suggests that repeated antipsychotic treatment may disrupt avoidance responding by two distinct mechanisms: (a) weakening the motivational salience of the CS and (b) providing an interoceptive drug state that maintains the weakening effect on motivational salience of the CS over time. To carefully extrapolate to clinical treatment, we would propose a hypothesis that antipsychotic drugs may achieve their antipsychotic effect through a dual action: (a) selectively weakening the aberrant motivational salience of stimuli (e.g., psychotic thoughts or abnormal perceptions, internal and external cues) (Kapur, 2003); and (b) producing a drug interoceptive state that allows the weakening effect on the motivational salience of stimuli to be maintained over time. Practically, this study may also provide support for the intermittent drug treatment regimen to be tried in the clinic. Currently, the most common practice in the clinic is to treat patients with antipsychotics on the daily basis which produces approximately $60 \%-80 \%$ of dopamine $\mathrm{D}_{2}$ receptor occupancy (Kapur, 1998). As it is widely known that antipsychotic treatment carries many side effects, including EPS and excess weight gain, an intermittent schedule may be an efficient and safer alternative warranting further research. A recent study shows that dosing every 2-3 days is sufficient to maintain antipsychotic efficacy in schizophrenic patients (Remington, et al., 2005). These findings may suggest that upon initial exposure, physiological events may be initiated that enhance the antipsychotic's effects beyond its presence at the receptor, thereby not requiring constant binding at the receptor every day to be efficacious.

In summary, this study confirms that repeated antipsychotic treatment induces an interoceptive drug state that mediates the potentiated antiavoidance effect of antipsychotics (HAL, OLZ and RIS) over multiple drug test sessions. This drugstate-dependent 'memory-like' mechanism allows animals to make avoidance responses according to the drug state that they experience and can last for weeks. This mechanism may also be responsible for the clinical effects of repeated antipsychotic treatments in schizophrenia.

Acknowledgments

This study was funded in part by a support from the Nebraska Tobacco Settlement Biomedical Research Development Funds, and NARSAD Young Investigator Award to ML. We thank Tao Sun, Wei He, and Jing Chen for their excellent technical assistance. We thank the two anonymous reviewers for their insightful comments.

\section{References}

Agid, O, Kapur, S, Arenovich, T, Zipursky, RB (2003) Delayed-onset hypothesis of antipsychotic action: a hypothesis tested and rejected. Arch Gen Psychiatry 60: 1,228-1,235.

Agid, O, Seeman, P, Kapur, S (2006) The "delayed onset" of antipsychotic action-an idea whose time has come and gone. J Psychiatry Neurosci 31: 93-100.

Aravagiri, M, Teper, Y, Marder, SR (1999) Pharmacokinetics and tissue distribution of olanzapine in rats. Biopharm Drug Dispos 20: 369-377.

Arnt, J (1982) Pharmacological specificity of conditioned avoidance response inhibition in rats: inhibition by neuroleptics and correlation to dopamine receptor blockade. Acta Pharmacol Toxicol (Copenh) 51: 321-329.

Bateup, HS, Svenningsson, P, Kuroiwa, M, Gong, S, Nishi, A, Heintz, $\mathrm{N}$, et al. (2008) Cell type-specific regulation of DARPP-32 phosphorylation by psychostimulant and antipsychotic drugs. Nat Neuro- 
sci 11: 932-939.

Bolles, RC (1970) Species-specific defense reactions and avoidance learning. Psychol Rev 77: 32-48.

Cheng, YF, Paalzow, LK (1992) Linear pharmacokinetics of haloperidol in the rat. Biopharm Drug Dispos 13: 69-76.

Emsley, R, Rabinowitz, J, Medori, R (2006) Time course for antipsychotic treatment response in first-episode schizophrenia. Am J Psychiatry 163: 743-745.

Glick, ID, Shkedy, Z, Schreiner, A (2006) Differential early onset of therapeutic response with risperidone vs conventional antipsychotics in patients with chronic schizophrenia. Int Clin Psychopharmacol 21: 261-266.

Goudie, AJ, Smith, JA, Taylor, A, Taylor, MA, Tricklebank, MD (1998) Discriminative stimulus properties of the atypical neuroleptic clozapine in rats: tests with subtype selective receptor ligands. Behav Pharmacol 9: 699-710.

Grande, C, Zhu, H, Martin, AB, Lee, M, Ortiz, O, Hiroi, N, et al. (2004) Chronic treatment with atypical neuroleptics induces striosomal FosB/DeltaFosB expression in rats. Biol Psychiatry 55: 457-463.

Kapur, S (1998) A new framework for investigating antipsychotic action in humans: lessons from PET imaging. Mol Psychiatry 3: 135-140.

Kapur S (2003): Psychosis as a state of aberrant salience: a framework linking biology, phenomenology, and pharmacology in schizophrenia. Am J Psychiatry 160: 13-23.

Kapur, S, Arenovich, T, Agid, O, Zipursky, R, Lindborg, S, Jones, B (2005) Evidence for onset of antipsychotic effects within the first 24 hours of treatment. Am J Psychiatry 162: 939-946.

Kapur, S, VanderSpek, SC, Brownlee, BA, Nobrega, J (2003) Antipsychotic dosing in preclinical models is often unrepresentative of the clinical condition: a suggested solution based on in vivo occupancy. J Pharmacol Exp Ther 305: 1-7.

Kippin, TE, Kapur, S, van der Kooy, D (2005) Dopamine specifically inhibits forebrain neural stem cell proliferation, suggesting a novel effect of antipsychotic drugs. J Neurosci 25: 5,815-5,823.

Konradi, C, Heckers, S (2001) Antipsychotic drugs and neuroplasticity: insights into the treatment and neurobiology of schizophrenia. Biol Psychiatry 50: 729-742.

Leucht, S, Busch, R, Hamann, J, Kissling, W, Kane, JM (2005) Earlyonset hypothesis of antipsychotic drug action: a hypothesis tested, confirmed and extended. Biol Psychiatry 57: 1,543-1,549.

Li, M, Fletcher, PJ, Kapur, S (2007) Time course of the antipsychotic effect and the underlying behavioral mechanisms. Neuropsychopharmacology 32: 263-272.

$\mathrm{Li}, \mathrm{M}, \mathrm{He}, \mathrm{W}$, Mead, A (2009) Olanzapine and risperidone disrupt conditioned avoidance responding in phencyclidine or amphetamine pretreated rats by selectively weakening motivational salience of conditioned stimulus. Behav Pharmacol 20: 84-98.

Maes, JH, Vossen, JM (1997) Conditional control by midazolam and amphetamine in a rapid appetitive discrimination procedure. Eur J Pharmacol 319: 5-11.

Mead, A, Li, M, Kapur, S (2008) Clozapine and olanzapine exhibit an intrinsic anxiolytic property in two conditioned fear paradigms: contrast with haloperidol and chlordiazepoxide. Pharmacol Biochem Behav.

Miyamoto, S, Duncan, GE, Marx, CE, Lieberman, JA (2005) Treatments for schizophrenia: a critical review of pharmacology and mechanisms of action of antipsychotic drugs. Mol Psychiatry 10: 79-104.

Natesan, S, Reckless, GE, Nobrega, JN, Fletcher, PJ, Kapur, S (2006) Dissociation between in vivo occupancy and functional antagonism of dopamine $\mathrm{D}_{2}$ receptors: comparing aripiprazole to other anti-psychotics in animal models. Neuropsychopharmacology 31: 1,854-1,863.

Nguyen, TV, Kosofsky, BE, Birnbaum, R, Cohen, BM, Hyman, SE (1992) Differential expression of c-fos and zif268 in rat striatum after haloperidol, clozapine, and amphetamine. Proc Natl Acad Sci USA 89: 4,270-4,274.

Overton, DA (1979) Preclinical measurement of the amount of statedependent learning produced by psychoactive drugs [proceedings]. Psychopharmacol Bull 15: 51-52.

Porter, JH, Prus, AJ, Vann, RE, Varvel, SA (2005) Discriminative stimulus properties of the atypical antipsychotic clozapine and the typical antipsychotic chlorpromazine in a three-choice drug discrimination procedure in rats. Psychopharmacology (Berl) 178: 67-77.

Porter, JH, Varvel, SA, Vann, RE, Philibin, SD, Wise, LE (2000) Clozapine discrimination with a low training dose distinguishes atypical from typical antipsychotic drugs in rats. Psychopharmacology (Berl) 149: 189-193.

Raedler, TJ, Schreiner, A, Naber, D, Wiedemann, K (2007) Early onset of treatment effects with oral risperidone. BMC Psychiatry 7: 4.

Remington, G, Seeman, P, Shammi, C, Mann, S, Kapur, S (2005) "Extended" antipsychotic dosing: rationale and pilot data. J Clin Psychopharmacol 25: 611-613.

Robertson, GS, Fibiger, HC (1992) Neuroleptics increase c-fos expression in the forebrain: contrasting effects of haloperidol and clozapine. Neuroscience 46: 315-328.

Robertson, GS, Matsumura, H, Fibiger, HC (1994) Induction patterns of Fos-like immunoreactivity in the forebrain as predictors of atypical antipsychotic activity. J Pharmacol Exp Ther 271: 1,058-1,066.

Samaha, AN, Reckless, GE, Seeman, P, Diwan, M, Nobrega, JN, Kapur, S (2008) Less is more: antipsychotic drug effects are greater with transient rather than continuous delivery. Biol Psychiatry 64: 145-152.

Samaha, AN, Seeman, P, Stewart, J, Rajabi, H, Kapur, S (2007) “Breakthrough" dopamine supersensitivity during ongoing antipsychotic treatment leads to treatment failure over time. J Neurosci 27: 2,9792,986 .

Schechter, MD, Cook, PG (1975) Dopaminergic mediation of the interoceptive cue produced by d-amphetamine in rats. Psychopharmacologia 42: 185-193.

Sun, T, Hu, G, Li, M (2009) Repeated antipsychotic treatment progressively potentiates inhibition on phencyclidine-induced hyperlocomotion, but attenuates inhibition on amphetamine-induced hyperlocomotion: relevance to animal models of antipsychotic drugs. Eur J Pharmacol 602: 334-342.

van Beijsterveldt, LE, Geerts, RJ, Leysen, JE, Megens, AA, Van den Eynde, HM, Meuldermans, WE, et al. (1994) Regional brain distribution of risperidone and its active metabolite 9-hydroxy-risperidone in the rat. Psychopharmacology (Berl) 114: 53-62.

Wadenberg, ML, Soliman, A, VanderSpek, SC, Kapur, S (2001) Dopamine $\mathrm{D}(2)$ receptor occupancy is a common mechanism underlying animal models of antipsychotics and their clinical effects. Neuropsychopharmacology 25: 633-641. 